\title{
Comparison of two endoscopic spine surgical techniques
}

\author{
André Luís Sebben ${ }^{1 *} \odot$, Álynson Larocca Kulcheski² $\odot$, Xavier Soler I Graells ${ }^{\circledR}$, \\ Marcel Luiz Benato ${ }^{2} \odot$, Pedro Grein Del Santoro ${ }^{2}$
}

\section{SUMMARY}

OBJECTIVE: The objective of this study is to compare the clinical outcome among patients who are surgically treated for lumbar disc herniation by transforaminal and interlaminar endoscopy techniques.

METHODS: For the treatment of lumbar disc herniation, 31 patients were assigned to undergo the interlaminar technique and 24 patients the transforaminal technique. They were evaluated using visual analog scale and Oswestry disability index in the preoperative period, in the first postoperative period, and in the 12th month after the procedure. The clinical results between the two techniques were then compared.

RESULTS: Overall, $89.1 \%$ of the patients obtained good results, with $12.5 \%$ complications in the transforaminal technique and $9.6 \%$ in the interlaminar technique.

CONCLUSION: Although both the endoscopic techniques, compared in this study, are safe and effective for the surgical treatment of lumbar herniated disc, the interlaminar technique presented significantly better results and lower rates of complications than the transforaminal technique.

KEYWORDS: Spine. Intervertebral disk displacement. Endoscopy. Decompression, Surgical. Sciatica.

\section{INTRODUCTION}

Herniated disc is a disabling pathology. In most cases, its treatment is conservative and good results are obtained, but when this treatment fails, the best option is the surgical treatment ${ }^{1}$. This treatment has varied over time, from laminectomy and discectomy to the most recent percutaneous surgeries. With the popularization of minimally invasive spine surgeries, percutaneous endoscopic lumbar discectomy has increasingly become an alternative for the treatment of herniated discs, due to the advantages of this procedure. Two techniques that are mostly used in the endoscopic spine procedures are: the transforaminal and the interlaminar routes.

In the transforaminal technique, the patient is positioned in the ventral decubitus position; the midline and the lower and upper vertebral plateaus of the desired level are marked under visualization of the image intensifier, and lateral markings are the midline of 8,10 , and $12 \mathrm{~cm}$, which will be the possible entry points. The patient is submitted to light sedation, and at the entry point, an infiltration is performed with a local anesthetic without vasoconstrictor. The sedation must be light, because the patient should be conscious enough to alert if any nerve root is stimulated during the procedure. After this stage, the intervertebral disc is punctured, and discography with methylene blue or indigo carmine, associated with non-ionic contrast, is performed. Through the guides, the endoscope is inserted in the intervertebral disc and an indirect decompression of the intervertebral disc is performed (inside-out technique), followed by a thermal nucleoplasty. The entire procedure takes place through Kambin's safety triangle. It is indicated for the treatment of hernias located in the foraminal or extraforaminal

\footnotetext{
${ }^{1}$ Hospital de Clínicas da Universidade Federal do Paraná - Curitiba (PR), Brazil.

${ }^{2}$ Hospital do Trabalhador - Curitiba (PR), Brazil.

*Corresponding author: andresebben@gmail.com

Conflicts of interest: the authors declare there are no conflicts of interest. Funding: none.

Received on September 02, 2020. Accepted on September 03, 2020.
} 
region, mainly at the L2 to L5 lumbar spine. Generally, this approach is made difficult at the distal L5-S1 level by the anatomical interposition of the iliac crest ${ }^{2-4}$ (Figure 1).

In the interlaminar endoscopic discectomy, the patient is positioned in the ventral decubitus position, on a radiotransparent table, under general anesthesia. In this technique, general anesthesia is used because it is necessary to remove the neural root, which generates discomfort to the patient. The interlaminar window at the desired level is marked on the skin with the aid of the image intensifier, and a longitudinal access of $1 \mathrm{~cm}$ is made near the midline. An initial dilator is positioned in the interlaminar space, and the endoscope is introduced. First, the multifidus musculature is dissected into the yellow ligament, which is opened for exp osure of the descending root and perineal fat. The nerve root is removed and protected with the aid of a beveled cannula. The intervertebral disc is perforated and decompressed. At the end of the procedure, a thermal nucleoplasty is performed. In general, this technique is used for the levels L4/L5 and L5/S1, where a wide interlaminar interval is observed, which provides more working space. This procedure is indicated for central and central-lateral hernias ${ }^{3-5}$ (Figure 2).

The endoscopic surgical techniques evaluated in this study are not widely known to spine surgeons, and its practice in Brazil is still restricted to some reference centers. The presentation and comparison of results between the two main endoscopic approaches may help in the indication for each case.

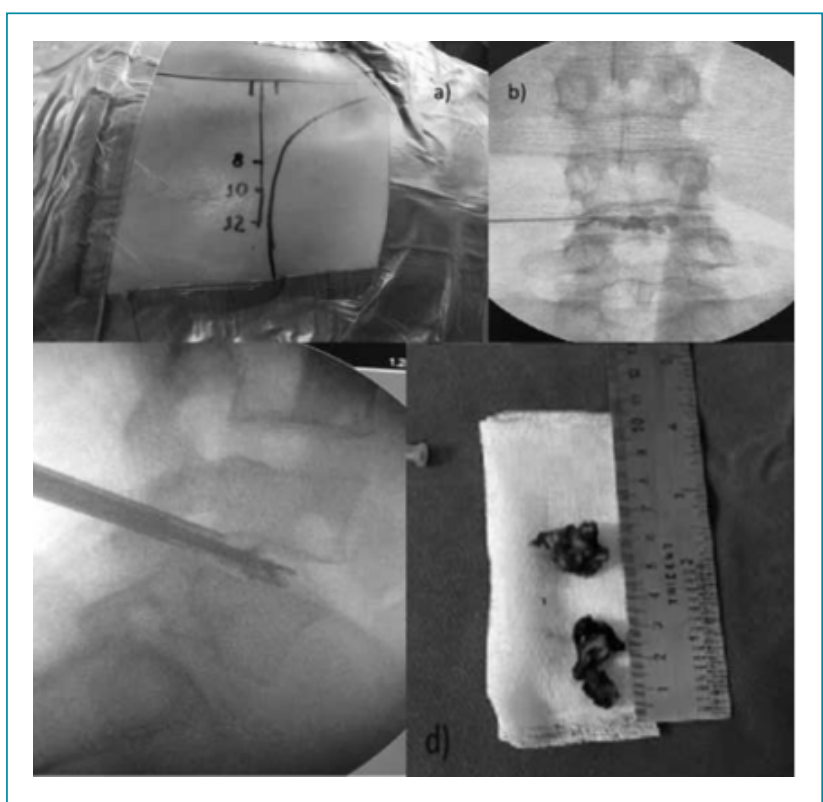

Figure 1. Percutaneous endoscopic transforaminal discectomy. (a) Skin markings, (b) anteroposterior view discography of radioscopy, (c) radioscopy profile view with demonstration of inside-out discectomy technique, and (d) disc material removed.
The objective of this study is to present two minimally invasive surgical techniques in the spine and compare the results obtained in the treatment of lumbar disc hernias.

\section{METHODS}

This longitudinal, observational, and prospective study was approved by the Research Ethics Committee under number CAAE 50750515.2.0000.5225. We grouped 55 patients who underwent the surgical treatment for lumbar disc herniation in a tertiary hospital, a reference in the surgical treatment of the spine, by the percutaneous endoscopic lumbar discectomy technique. Inclusion criteria for this study were as follows: patients of both genders and aged between 18 and 99 years, who had not been submitted to the previous procedures in the spine and had failed to undergo the conservative treatment of lumbar disc herniation, administered for at least 3 months, and who presented herniated disc in at most two levels in the lumbar region. These patients were subdivided into two groups: the endoscopic transforaminal technique and the interlaminar technique. Clinical evaluation was performed, and the Oswestry 2.0 questionnaire and the visual analog pain scale were used to quantify the results, applied on the following dates: the day before surgery, the first day after, and at 1 year after the surgery. The epidemiological data such as gender and age were also evaluated, as well as the postoperative complications such as surgical site infection, neurological alteration

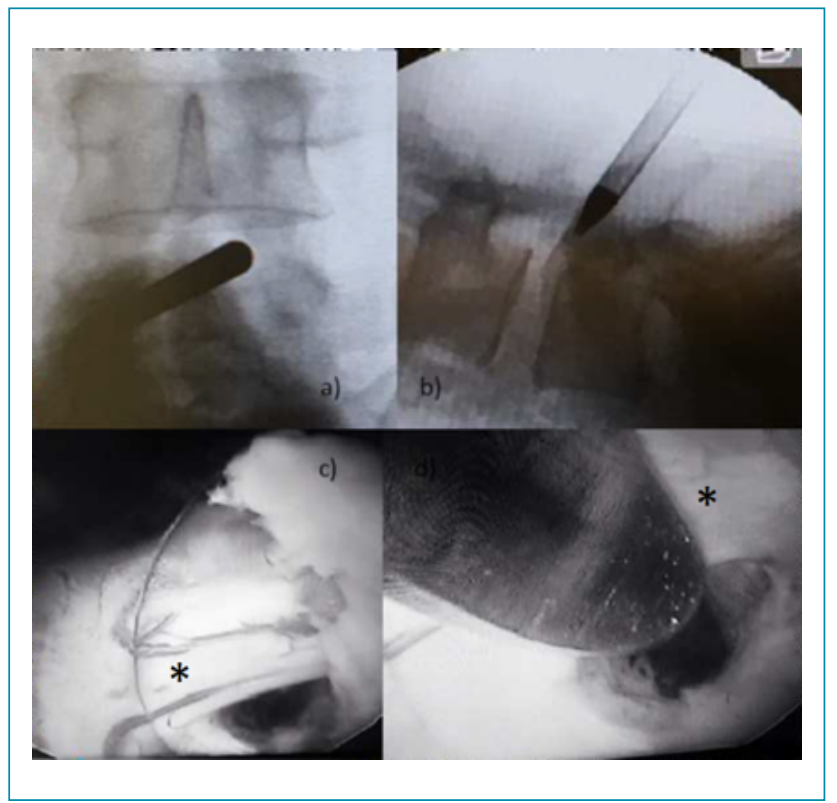

Figure 2. Interlaminar percutaneous endoscopic discectomy. (a) Point of entry into anteroposterior vision of radioscopy, (b) point of entry into radioscopy profile view, (c) yellow ligament opening and neural root being evidenced, and (d) probe by removing the root after discectomy. *Marking the neural root. 
(paresis, paraesthesias), neural lesions, iatrogenic durotomy with or without lichen fistula, and relapse of herniated disc. The clinical outcome was compared separately between males and females in search of statistically significant differences between the sexes.

Patients who underwent the surgical treatment for lumbar disc herniation by open surgical technique, those over 80 years of age or under 18 years of age, and nonconsenting individuals were excluded.

The study was conducted from December 2014 to November 2015 , totaling 1 year of endoscopic surgical procedures, and followed prospectively for 12 months postoperatively.

The material used for the procedures was the Vertebris Richard Wolf endoscopes ${ }^{\circledR}$.

Two different endoscopic surgical techniques were used: transforaminal and interlaminar. Patients with central and central-lateral disc hernias were submitted to the interlaminar technique. On the other hand, those with foraminal and extraforaminal herniations were submitted to the transforaminal technique. When the herniation was foraminal or extraforaminal at the L5/S1 level, the transforaminal technique was performed only in cases where there was no anatomical barrier of the iliac bone in the surgical access. Patients with this anatomic limitation were excluded because they were submitted to non-endoscopic surgical technique. The procedures were performed by four different surgeons of the Spine Group, all of whom had the same training and previous experience in performing the endoscopic surgical technique.

The $\mathrm{R}$ software (R Core Team, 2015, version 3.2.3) was used for data analysis. As a statistical method, a multivariate analysis was conducted with a regression model for the longitudinal data. A significance level of 5\% was adopted, and considered significant if $\mathrm{p}<0.05$.

\section{RESULTS}

All the 55 patients included in this study underwent the surgical treatment of lumbar disc herniation by lumbar endoscopic technique. There were 29 female patients $(52.8 \%)$ with a mean age of 37.8 years and 26 male patients $(47.2 \%)$ with a mean age of 42.9 years. Of them, $24(43.7 \%)$ underwent transforaminal technique and $31(56.3 \%)$ interlaminar technique. The predominant operated levels were L4/L5 (20 cases) and L5/S1 (19 cases). Only 4 patients were operated at the L3/L4 level. Of this, 12 patients had a two-level approach in surgery.

The average score of the Oswestry scale in the preoperative period was 26.2, which was dropped to 5.5 on the first day after the procedure and 12 months after the procedure, it was 5.3, regardless of the surgical technique used. In the transforaminal technique, the mean preoperative rate was 27.5 , which dropped to 6.3 on the first day after the procedure and 12 months after the procedure, it was 8.0; in the interlaminar technique, the values were $25.1,4.8$, and 3.1, respectively. The mean preoperative pain scaling, independent of the technique, was 8.4; on the first postoperative day, it was 2.3 ; and at the 12 th month, it was 1.9. In the transforaminal technique, the preoperative mean was 8.3 , which was 2.9 on the first day, and 3.2 after 12 months; in the interlaminar technique, the values were $8.5,1.7$, and 1 , respectively. Both were statistically significant with $\mathrm{p}<0.0001$. There was no statistically significant difference between males and females when using a $\mathrm{p}<0.05$.

There was an incidence of $10.9 \%$ of complications in general, with three complications in each group, representing $12.5 \%$ rate of complications in the transforaminal group and $9.6 \%$ in the interlaminar group. The complications evaluated were as follows: neurological alteration, surgical site infection, durotomy with or without lichen fistula, and relapse of herniated disc. No patient had surgical site infection. Two durotomies occurred during the procedures $(3.6 \%)$, both in patients submitted to the interlaminar technique, one being asymptomatic without clinical repercussions and the other studied with lichen fistula associated with postural headache with spontaneous resolution after $48 \mathrm{~h}$ of rest and without surgical reintervention. There were no cases of complete neural injury, but three patients (5.4\%) had paresthesia in the lower limbs, two (8.3\%) underwent transforaminal technique, and one (3.2\%), interlaminar technique. Only two patients were submitted to surgical reintervention due to any of these complications, representing $3.6 \%$ of the cases. One of the patients was reoperated due to relapse of the disc herniation (transforaminal group, 4.1\%), and the other due to technical difficulty in removing all the disc herniation which was calcified (interlaminar group, 3.2\%). This last patient evolved with paresthesia of the interlaminar group (Figure 3).

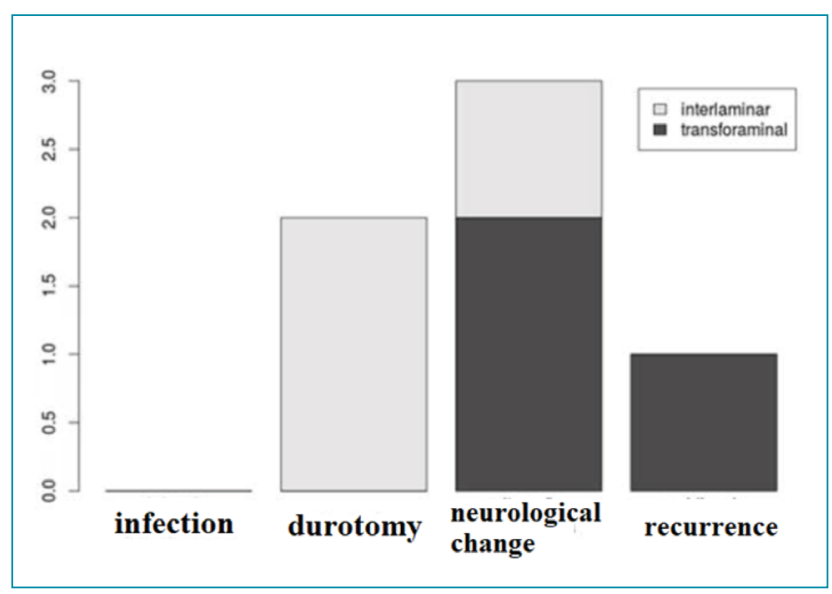

Figure 3. Complications between the two study groups. 


\section{DISCUSSION}

Among the endoscopic techniques of the spine, the most used are transforaminal and interlaminar ${ }^{9}, 10$. We observed a slight predominance of the interlaminar technique (56.3\% of the cases), considering the higher incidence of centro-lateral disc hernias in the studied population. In this study, the patients were evaluated preoperatively, on the first day after the procedure, and after 12 months. Oswestry disability index (ODI) and visual analog scale (VAS) were evaluated and showed that the patients achieved a statistically significant improvement $(\mathrm{p}<0.0001)$ with the endoscopic treatment of lumbar disc herniation, and $89.1 \%$ of the patients had a good response to the surgical treatment. These values are higher than the success rates of the gold standard, which varies from 70 to $84 \%$ of good results, according to the study of Dohrmann et al., who analyzed 39,000 patients with lumbar disc herniation ${ }^{11}$. Separating the surgical techniques, the transforaminal technique had a slightly lower result than interlaminar, mainly in the evaluation done after 12 months of the procedure $(\mathrm{p}<0.05)$. On the first postoperative day, the improvement of pain complaints assessed by VAS was greater in the interlaminar group. The rate of complications was $12.5 \%$ in the transforaminal technique and $9.5 \%$ in the interlaminar, in which the values were comparable to the gold standard, according to the study of Shriver et al. The incidence of durotomy in our study was similar to that in the literature for the gold standard, which is approximately $3.1 \%{ }^{12,13}$. There was a higher incidence of postoperative paresthesia in patients who underwent the transforaminal technique ( 8.3 vs. 3.2\%). A possible explanation for the higher incidence of postoperative pain complaints in patients submitted to transforaminal technique may be due to stimulation of the dorsal root ganglion during the insertion of the instrument. The literature shows a possibility that the dorsal root ganglion may present within the triangular safety zone described in the endoscopic procedures ${ }^{14}$. Stimulation could be associated with the most incident neuropathic complaints in patients undergoing the transforaminal technique.

The literature reoperation rate for open microdiscectomy according to the study by Soliman et al. was $18.5 \%{ }^{15}$. Aichmair et al., however, showed a higher rate, reaching $25 \%{ }^{16}$. Both presented a follow-up of at least 5 years. Our reoperation rate was only $3.6 \%$ (two patients), and in the transforaminal technique, it was $4.1 \%$ (one patient) and in the interlaminar technique, it was 3.2\% (one patient). In the transforaminal group, the reoperation was occurred due to the herniated disc recurrence. This patient presented a herniated disc which occupied more than $50 \%$ of the vertebral canal in the preoperative period. The literature shows that these cases are the most difficult for the complete removal of the hernia by endoscopic route. However, this patient was reoperated by the same surgical technique and presented satisfactory improvement of symptoms after the second procedure ${ }^{17}$. In the interlaminar approach, the reoperation occurred due to a calcified hernia, which made the procedure difficult by the endoscopic route, being converted to open microdiscectomy ${ }^{18}$.

Complications are the very important factors in assessing the safety of a surgical procedure. A recent meta-analysis compared the clinical outcomes between open microdiscectomy and endoscopic microdiscectomy and showed that the rate of complications was similar in both groups, suggesting that the minimally invasive procedure is safe for the surgical treatment of lumbar herniated disc ${ }^{19-22}$.

As a limitation of this study, the postoperative follow-up of only 12 months and a limited number of patients in our casuistry should be taken into consideration. The literature review shows that the main postoperative complications only occur during the 1 st year after the procedure, so most of them were contemplated in this follow-up period. Another limiting factor is that we compared the surgical techniques at different disc levels. It is known that the neurological symptoms are different in each vertebral segment. However, the indications are described and enshrined in the literature. This study is a part of a research line intended to present the updated data in future publications ${ }^{23,24}$. The level of evidence in this study is five. Spine endoscopy is a promising spine technique; however, its learning curve is long and not all the specialized services have access to the method. Another limiting factor is its high cost, making it difficult to expand in the medical environment, and increasing healthcare costs.

In the future, it is expected that spinal endoscopy will have its reach extended and its benefits will bring better clinical results to patients. Studies in this sense, with larger samples and in different centers, need to be conducted to reinforce the findings of this study.

\section{CONCLUSIONS}

Spine endoscopy for the treatment of lumbar disc herniation showed approximately $90 \%$ of good results, regardless of the technique used. Both the endoscopic techniques performed are safe and effective for the surgical treatment of lumbar disc herniation, but the interlaminar technique presented significantly better results and lower rates of complications than the transforaminal technique.

\section{AUTHORS" CONTRIBUTIONS}

ALS: Conceptualization, Data Curation, Investigation, Methodology, Writing - Original Draft, Writing - Review and Editing. ALK: Conceptualization, Formal Analysis, Methodology, Writing - Original Draft, Writing - Review and Editing. PGS: Investigation, Writing - Original Draft, Writing - Review and Editing. MLB: Conceptualization, Investigation, Writing Original Draft, Writing - Review and Editing. XSG: Investigation, Project Administration, Writing - Review and Editing. 


\section{REFERENCES}

1. Kreiner DS, Hwang SW, Easa JE, Resnick DK, Baisden JL, Bess $\mathrm{S}$, et al. An evidence-based clinical guideline for the diagnosis and treatment of lumbar disc herniation with radiculopathy. Spine J. 2014;14(1):180-91. https://doi.org/10.1016/j. spinee.2013.08.003

2. Yeung AT, Tsou PM. Posterolateral endoscopic excision for lumbar disc herniation: Surgical technique, outcome, and complications in 307 consecutive cases. Spine (Phila Pa 1976). 2002;27(7):72231. https://doi.org/10.1097/00007632-200204010-00009

3. Yeung AT. Minimally Invasive Disc Surgery with the Yeung Endoscopic Spine System (YESS). SurgTechnol Int. 1999;8:26777. PMID: 12451541

4. Yeung AT, Yeung CA. Advances in endoscopic disc and spine surgery: foraminal approach. SurgTechnol Int. 2003;11:25563. PMID: 12931309

5. Choi G, Lee SH, Raiturker PP, Lee S, Chae YS. Percutaneous endoscopic interlaminar discectomy for intracanalicular disc herniations at L5-S1 using a rigid working channel endoscope. Neurosurgery. 2006;58(Suppl 1):ONS59-68. https://doi. org/10.1227/01.neu.0000192713.95921.4a

6 Ruetten S, Komp M, Godolias G. A New full-endoscopic technique for the interlaminar operation of lumbar disc herniations using 6-mm endoscopes: prospective 2-year results of 331 patients. Minim Invasive Neurosurg. 2006;49(2):80-7. https://doi.org/10.1055/s-2006-932172

7. Ruetten S, Komp M, Merk H, Godolias G. Full-endoscopic interlaminar and transforaminal lumbar discectomy versus conventional microsurgical technique: a prospective, randomized, controlled study. Spine (Phila Pa 1976). 2008;33(9):931-9. https://doi.org/10.1097/BRS.0b013e31816c8af7

8. Apostolides PJ, Jacobowitz R, Sonntag VK. Lumbar discectomy microdiscectomy: "the gold standard". Clin Neurosurg. 1996;43:228-38. PMID: 9247807

9. Postacchini F, Postacchini R. Operative management of lumbar disc herniation: the evolution of knowledge and surgical techniques in the last century. Acta Neurochir Suppl. 2011;108:17-21. https://doi.org/10.1007/978-3-211-99370-5_4

10. Anichini G, Landi A, Caporlingua F, Beer-Furlan A, Brogna C, Delfini R, et al. Lumbar Endoscopic Microdiscectomy: Where Are We Now? An Updated Literature Review Focused on Clinical Outcome, Complications, and Rate of Recurrence. Biomed Res Int. 2015;2015:417801. https://doi.org/10.1155/2015/417801

11. Dohrmann GJ, Mansour N. Long-Term Results of Various Operations for Lumbar Disc Herniation: Analysis of over 39,000 Patients. Med Princ Pract. 2015;24(3):285-90. https:// doi.org/10.1159/000375499

12. Shriver MF, Xie JJ, Tye EY, Rosenbaum BP, Kshettry VR, Benzel EC, et al. Lumbar microdiscectomy complication rates: a systematic review and meta-analysis. Neurosurg Focus. 2015;39(4):E6. https://doi.org/10.3171/2015.7.FOCUS15281
13. Desai A, Ball PA, Bekelis K, Lurie JD, Mirza SK, Tosteson TD, et al. Outcomes after incidental durotomy during first-time lumbar discectomy. J Neurosurg Spine. 2011;14(5):647-53. https://doi.org/10.3171/2011.1.SPINE10426

14. Vialle E, Vialle LR, Contreras W, Jacob Junior C. Estudo anatômico da relação do gânglio da raiz dorsal com o disco intervertebral na coluna lombar. Rev Bras Ortop. 2015;50(4):450-4. https:// doi.org/10.1016/j.rboe.2015.06.013

15. Soliman J, Harvey A, Howes G, Seibly J, Dossey J, Nardone E. Limited microdiscectomy for lumbar disk herniation: a retrospective long-term outcome analysis. J Spinal Disord Tech. 2014;27(1):E8-13. https://doi.org/10.1097/ BSD.0b013e31828da8f1

16. Aichmair A, Du JY, Shue J, Evangelisti G, Sama AA, Hughes $A P$, et al. Microdiscectomy for the treatment of lumbar disc herniation: an evaluation of reoperations and long-term outcomes. Evid Based Spine Care J. 2014;5(2):77-86. https:// doi.org/10.1055/s-0034-1386750

17. Lee SH, Kang BU, Ahn Y, Choi G, Choi YG, Ahn KU, et al. Operative failure of percutaneous endoscopic lumbar discectomy: a radiologic analysis of 55 cases. Spine (Phila Pa 1976). 2006;31(10):E285-90. PMID: 16648734

18. Dabo X, Ziqiang C, Yinchuan Z, Haijian N, Kai C, Yanbin $L$, et al. The Clinical results of percutaneous endoscopic interlaminar discectomy (PEID) in the treatment of calcified lumbar disc herniation: a case-control study. Pain Physician. 2016;19(2):69-76. PMID: 26815251

19. He J, Xiao S, Wu Z, Yuan Z. Microendoscopic discectomy versus open discectomy for lumbar disc herniation: a meta-analysis. Eur Spine J. 2016;25(5):1373-81. https://doi.org/10.1007/ s00586-016-4523-3

20. Ruetten S, Komp M, Merk H, Godolias G. Recurrent lumbar disc herniation after conventional discectomy: a prospective, randomized study comparing full-endoscopic interlaminar and transforaminal versus microsurgical revision. J Spinal Disord Tech. 2009;22(2):122-9. https://doi.org/10.1097/ BSD.0b013e318175ddb4

21. Hsu HT, Chang SJ, Yang SS, Chai CL. Learning curve of fullendoscopic lumbar discectomy. Eur Spine J. 2013;22(4):727-33. https://doi.org/10.1007/s00586-012-2540-4

22. Ahn Y. Endoscopic spine discectomy: indications and outcomes. Int Orthop. 2019;43(4):909-16. https://doi.org/10.1007/ s00264-018-04283-w

23. Butler AJ, Alam M, Wiley K, Ghasem A, Rush III AJ, Wang JC. Endoscopic Lumbar Surgery: The State of the Art in 2019. Neurospine. 2019;16(1):15-23. https://doi.org/10.14245/ ns. 1938040.020

24. Hasan S, Hofstetter CP. Endoscopic spine surgery past, present, and future. Bull Hosp Jt Dis (2013). 2019;77(1):75-84. PMID: 30865869 